\title{
Ser "moreno", ser "negro": memórias de experiências de racialização no litoral norte do Rio Grande do Sul no século XX
}

\author{
Being "moreno", being "negro": \\ memories of racialization experiences in the north coast of \\ Rio Grande do Sul in the XXth century \\ Rodrigo de Azevedo Weimer
}

\section{Memória, racialização e negritude}

O propósito deste artigo é verificar cortes e continuidades nas noções de autodesignação de natureza racial, entre meados do século XX e a contemporaneidade, por descendentes de escravos pertencentes a uma mesma família. Assim sendo, foram contrastados os qualificativos dessa natureza empregados

Rodrigo de Azevedo Weimer é doutor em História pela Universidade Federal Fluminense e bolsista de pós-doutorado na Universidade do Vale do Rio dos Sinos (Unisinos), Rio Grande do Sul, Brasil. Agência de financiamento CNPq (rod_weimwr@hotmail.com).

Artigo recebido em 13 de maio e aprovado para publicação em 2 de setembro de 2013.

Est. Hist., Rio de Faneiro, vol. 26, no 52, p. 409-428, julho-dezembro de 2013. 


\section{Rodrigo de Azevedo Weimer}

por netos - atualmente octogenários ou nonagenários - e bisnetos de escravos da fazenda do Morro Alto - em seus 50 ou 60 anos.

A investigação proposta conecta duas abordagens da pesquisa histórica contemporânea: a história da memória - que reside no entendimento de que os processos mnemônicos possuem uma historicidade que cumpre investigar (Rousso, 1998; Hartog, 2003) ${ }^{1}$ - e a percepção das relações sociorraciais a partir da noção de racialização - que propõe a destituição do caráter substantivo subjacente à noção de "raça" e seu entendimento como resultado de uma construção histórica processual (Sansone, 2003; Mattos, 2004).

Ao identificar brevemente os parâmetros teóricos para a análise desenvolvida, busco assinalar como os sujeitos sociais investigados se lembram das categorias sociais. Se a experiência vivida é importante - nela se ampara a memória -, também é de interesse histórico verificar como a dimensão racial foi recordada pelas diferentes gerações. A partir de tal problemática buscarei compreender o porquê de em determinado momento haver uma percepção de ser "morenos" e, posteriormente, "negros".

O segundo termo foi positivado no Brasil ao longo do século XX, não possuindo, a priori, um caráter privilegiado como designação política das mobilizações étnico-raciais. Esse caráter resulta de complexo processo histórico. Gomes (2005) apontou como alguns movimentos sociais entre a abolição da escravidão e o Estado Novo tomaram para si a designação de "negros" como forma de mobilização política: Guarda Negra, no imediato pós-abolição, Mocidade Negra Brasileira, na década de 1920, Frente Negra Brasileira e Legião Negra, na década de 1930.

Apesar da precoce politização, há que se admitir que se conservou entre boa parte da população a identificação de significados pejorativos associados à condição “negra”. A té fins do século XIX, lembra Hebe Mattos (2004: 17), o significante remetia à condição cativa. Sheriff (2001: 218) também assinala a associação histórica en tre o termo e a condição servil. Conforme veremos, ela se mantém - ou melhor, se atualiza - nas falas dos entrevistados mais idosos, não sempre como sinônimo de condição escrava, mas certamente como algo que implicava condições humanas e de trabalho degradantes. ${ }^{2}$

Existe um certo consenso em torno do fato de que a difusão do termo "negro" associado ao orgulho étnico-racial remete à mobilização contra a ditadura civil-militar de 1964-1985. Amílcar Araujo Pereira analisou esse processo, destacando o surgimento de uma certa "consciência de negritude" a partir de meados da década de 1970, culminando na fundação do Movimento Negro Unificado em 1978 (Pereira, 2010: 61-67). A positivação da categoria "negro" marcou profundamente a sociedade brasileira a partir dos anos de 1980, de tal forma que o significado contemporâneo foi eventualmente naturalizado. 
Assim sendo, em face da mobilização contemporânea, causa estranheza o fato de os idosos conferirem à designação "moreno" uma dimensão de autoatribuição. No entanto, é isso que meus dados empíricos demonstram. Recuso-me à leitura da "falta de consciência" ou da "ambição de branqueamento". Não dialogo, aqui, com qualquer trabalho acadêmico em particular, e sim com o deslocamento semântico empreendido pelo movimento social. Segundo Sheriff (2001: 216): "O movimento negro insiste em que negra é qualquer pessoa de cor, com exceção dos indígenas. Alguns brasileiros de classe média, incluindo acadêmicos, hoje atendem ao apelo do movimento e não falam de pretos, mulatos e morenos, e sim de negros".

Um entendimento diverso não possui apenas fundamentos intelectuais, mas também políticos. Não é legítimo destituir os idosos - que talvez tenham enfrentado situações de racismo ainda mais intensas do que a geração seguinte - de uma suposta "consciência" atingida apenas entre seus filhos. Uma hipótese norteadora é a de que os mais moços só puderam "virar negros" seguindo rumos apontados por "pais morenos".

\section{Onde?}

A antiga fazenda do Morro Alto - na qual viveram os escravos ancestrais da família entrevistada - situava-se onde, na atualidade, está a divisa entre os municípios de Osório e Maquiné, ${ }^{3}$ no litoral norte do Rio Grande do Sul. Compreendia diversas localidades, entre as quais a denominada Morro Alto, onde hoje se encontra o entroncamento da estrada RS-407 com um braço morto da BR-101. A leste, seguia rumo à praia de Capão da Canoa ao longo da RS-407, por uma planície denominada Faxinal do Morro Alto, até o canal denominado Barra do João Pedro.

A fazenda, grosso modo, encontrava-se en tre as lagoas dos Quadros e Pinguela no sentido norte-sul e entre o divisor de águas da serra e o dito canal, no sentido leste-oeste. No século XIX, nas encostas se plantava a cana-de-açúcar, utilizada na produção de aguardente, enquanto as terras baixas eram voltadas para a criação de gado. A intensa escravaria então empregada é explicativa da preponderante população negra que ainda ali vive, e que, além da lavoura de subsistência, se dedica às mesmas atividades econômicas do período escravista, à extração mineral, e também ao trabalho sazonal nas praias de veraneio.

O quadrante nordeste do Rio Grande do Sul, ao longo do tempo, teve uma importância regional secundária, econômica e politicamente. Diante da criação de gado em grandes extensões na região da campanha e das charqueadas pelotenses, no século XIX, ou do desenvolvimento do minifúndio serrano e da 


\section{Rodrigo de Azevedo Weimer}

industrialização do vale do rio dos Sinos e da área metropolitana da capital, no século XX, os canaviais e usinas de Conceição do Arroio não tiveram a mesma relevância. Da mesma forma, suas praias não eram adequadas para a construção de portos.

Não obstante, apesar - e talvez por causa - de sua relativa marginalidade, a região aparece como um importante locus para a observação do problema proposto neste artigo. A decadência das propriedades escravistas do local, particularmente depois do fim do tráfico negreiro na segunda metade do século XIX que acabou com importante mercado para a aguardente - ensejou a formação de importante campesinato negro com acesso autônomo - costumeiro ou legalmente regularizado - à terra, inclusive a família em questão.

$\mathrm{Na}$ atualidade, ali existe uma série de localidades que compõem a tessitura de uma comunidade negra entrelaçada por laços de parentesco, práticas culturais e projetos políticos comuns: Morro Alto, Aguapés, Barranceira, Faxinal do Morro Alto, Ramalhete, Ribeirão do Morro Alto, Borba, Espraiado e, mais além, Prainha. Os descendentes de escravos da região, reconhecidos como remanescentes de quilombos, pleiteiam a titularização das terras que lhes são constitucionalmente de direito. Este aspecto é fundamental para a compreensão da dinâmica do uso de termos racializados.

\section{Quem? Quando?}

Conforme mencionado, o grupo investigado consiste em netos e bisnetos de um casal de escravos, Manoel Inácio e Felisberta, que haviam trabalhado na fazenda do Morro Alto. Pode-se pensar, a partir da perspectiva de Berlin (2006), o recorte geracional como uma abordagem profícua para a análise de trajetórias familiares, percebendo diferentes disposições e perspectivas para recordar e problematizar o passado. Tomando uma geração de pessoas na faixa de seus $80 / 90$ anos e outra em torno de 50/60, netos ou bisnetos de escravos, percebe-se um conhecimento mais amplo do passado escravista por parte dos idosos, que conviveram com avós cativos (Weimer, 2013). Os mais novos, no entanto, se mobilizam hoje em torno das demandas políticas vinculadas à emergência de etnicidade como remanescentes de quilombos. A pauta política do século XXI enseja uma revalorização da memória do cativeiro e o interesse por ouvir de seus pais as histórias de seus bisavós.

Sendo assim, meu "quando" se situa em um diálogo dos tempos (Mattos, 2005). Se esta investigação necessariamente remete ao passado - seja aos relatos das experiências de racialização de meados do século XX, seja, até mesmo, aos da realidade escravista - seu lugar é o hoje. Wolikow (1998) assinalou que toda his- 
Ser "moreno", ser "negro"

tória da memória é, antes de tudo, uma história do tempo presente. No caso de meu estudo, importa perceber de que maneiras as percepções vinculadas à racialização, dado que relatadas a partir do presente, se preservam, se transformam ou nele adquirem sentido.

Assim como o interesse acerca do passado escravista se reposiciona e retorna a um primeiro plano a partir da demanda comunitária étnica, os termos com que as experiências de racialização foram lembradas e vividas também adquiriram novos contornos. Netos e bisnetos de escravos referem-se a elas de formas mui distintas. Descrevê-las é o propósito do artigo.

\section{Como?}

Minha participação na equipe responsável pela elaboração do laudo de reconhecimento (2001/2002) desta comunidade foi a "porta de entrada" para o contato com a família em questão. A partir da relação de confiança estabelecida, foi possível a realização de novas entrevistas cerca de dez anos mais tarde, entre os anos finais da década de 2000 e iniciais da década de 2010, para minha tese de doutorado. Aquela pesquisa usou largamente da metodologia de história oral, aqui também empregada. Naqueles dez anos, contudo, não perdi o contato cotidiano com a família em questão, realizando sistemáticas visitas. Assim, o retorno se deu a partir de uma relação sólida, o que ensejou que fossem mais confidentes.

Foram entrevistados 14 integrantes da família da geração "mais antiga" e 10 entre os "mais novos". Foram feitas perguntas relevantes para a tese de doutorado para a qual foram produzidas: por exemplo, a narrativa das histórias de vida, suas e de seus ancestrais; a dinâmica da economia camponesa; a realidade do racismo; a participação familiar e a memória de diversos episódios da história brasileira, tais como a escravidão, a abolição e o período subsequente, a era Vargas, o êxodo rural de meados do século XX. Cumpre observar que não foram feitas perguntas acerca de categorias de classificação racial. Todas as observações desenvolvidas foram realizadas a partir da interpretação de categorias que surgiram de forma espontânea.

\section{Ser "moreno" e ser "preto" para os idosos}

$\mathrm{Na}$ fala dos idosos há uma sobreposição de duas dimensões dos termos "preto", "moreno" e "negro", dualidade que à primeira vista pode levar a confusões. Há antes de tudo uma dimensão cromática que, contudo, parece secundária diante de outros aspectos esmiuçados adiante. Em um primeiro momento, po- 


\section{Rodrigo de Azevedo Weimer}

rém, admitamos que esses qualificativos expressam tão-somente "cor", deixando de lado as implicações sociopolíticas dos termos raciais.

Por exemplo, quando entrevistei a senhora Eva Marques Correia, sua prima Diva Inácia Marques Terra estabeleceu um contraste entre a condição de "preta" e o qualificativo "clara". "Tu tá preta agora, mas tu era bem clara, só o cabelo que não lustrava."4 Situação - e há diversas nas entrevistas, esta é apenas um exemplo - em que se configura um contraste entre pessoas de pele mais escura ou mais clara. Evidencia-se o caráter de cor ocasionalmente assumido por tais características, mas por outro lado elas não são essencializadas, dado que "agora" Eva "estaria" preta, mas no passado "era" bem clara. Mesmo a cor é dinâmica...

Da mesma forma, o termo "moreno", podia ter uma conotação de cor. A mesma dona Diva, ao comparar o pai de sua prima com seu filho, os inscreve em uma gradação de cor na qual a categoria "moreno" surge como termo descritivo:

O pai [da prima Ercília] também não tinha cabelo ruim. Ele era moreno. Bem moreno. Moreno assim que nem o Cláudio [filho de Diva]. Mais ou menos. Um pouquinho mais claro, eu acho. Mas ele tinha cabelo bom $[\text { sic }]^{5}$

Outras falas, no entanto, ajudam a evidenciar dimensões diferentes da categoria "moreno", sugerindo não haver somente um caráter descritivo de aparência. É o que se percebe, por exemplo, quando Eva fala de uma prima "morena" cuja aparência não denunciava sua condição: "Era, era bem clara. Você não dizia que ela era morena. É bem clara." 6 Em outros termos, o fato de ser "clara" não a impedia de ser "morena", apenas tornava isso menos visível. Esta última era uma característica que independia de cor ou mistura racial. Podemos perceber o mesmo quando outra prima, Adiles Marques de Oliveira, destacou que sua mãe de criação era "morena assim, clara, de cabelo liso". Não obstante seu cabelo e a condição de "clara", foi considerada "morena". Em ambos os casos, à descrição de cor se sobrepunha a dimensão "morena". Investiguemos, pois, em que consistiria.

Na maioria dos casos, o caráter "cromático" - entendido como meramente descritivo da tez - é episódico. É uma exceção que não dá conta dos significados sociais latentes aos termos. No mais das vezes, as categorias arroladas possuíam uma dimensão mais profunda entre os narradores idosos: dimensões de hierarquização e, principalmente, pertença raciais. Expressivas, enfim, de processos de racialização. Em suma, a "cor" representa mais do que a tonalidade da pele. 
Constatei que ao se referirem aos bailes, por exemplo, que são o locus por excelência no qual se identificam as experiências de segregação racial, afirmava-se que "moreno" não entrava (Weimer, 2013). A categoria referia-se àqueles que, independentemente de variações de cor da tez, não eram considerados socialmente brancos e estavam proibidos de participar dos festejos. Um exemplo eloquente é dado por um senhor octogenário que preferiu não ser identificado. Ao indagá-lo sobre a segregação realizada em bailes, involuntariamente utilizei a categoria "negro". Ao responder-me, porém, o senhor em questão o fez, espontaneamente, com "moreno": "Antigamente, no tempo em que eu me criei, que minha gente me criaram e me assistiram, o baile de branco, moreno não entrava". ${ }^{7}$ Vale lembrar que aos olhos deste historiador - e de sua prima-segunda - esse senhor poderia ser considerado fenotipicamente branco. Não o era, no entanto, socialmente, quer por seus vínculos genealógicos, quer por seu pertencimento àquela coletividade de "morenos".

Embora não me sinta à vontade para citar seu nome, estou bastante confortável para explorar sua entrevista, sobretudo por sua situação singular entre os que ouvi: apesar de sua aparência, o senhor em questão sentia-se "moreno". Aqui, não se tratava de uma coloração de pele, mas da coletividade na qual se percebia inserido: por opção.

Entrevistador-Porque que o senhor disse que o senhor é branco, tem cor de branco, mas não é branco?

Entrevistado - Porque não me tenho como garantido por branco. Nunca tive esse orgulho de ser branco. Minha descendência é de família tudo moreno. Então eu queria ser moreno pra acompanhar minha família. A minha avó era preta que nem carvão. As outras minhas famílias é tudo preto... Compadre Teodoro, não é moreno? O senhor não viu ele lá? ${ }^{8}$

O excerto citado evidencia três aspectos. Em primeiro lugar, embora os termos "moreno" e "preto" remetam à tez quando referidos a indivíduos específicos - a avó e o compadre -, são intercambiáveis no que toca a coletividades. A descendência é de família "tudo moreno". "Minhas famílias" é tudo "preto". Em segundo lugar, a aparência não era suficiente para a inserção social na sociedade branca. Ele não se tinha "garantido" por branco, e isso decorria de uma situação familiar, genealógica, étnica, racial e mesmo de classe. ${ }^{9}$ Não interessava - perdoem os leitores a redundância - a dimensão cromática de sua "cor": era um camponês negro assim como os seus. Finalmente, ele não queria ser branco. Ele queria ser "moreno", para acompanhar seus familiares. ${ }^{10}$ 


\section{Rodrigo de Azevedo Weimer}

Se a "raça" era retórica (Crapanzano, 2001), também era mais do que isto. Resultava de disposições hierárquicas que conferiam lugares distintos às pessoas. Representava ainda uma adesão a determinada coletividade familiar e comunitária. ${ }^{11}$ Isso não significa que fosse mobilizada no sentido de ações políticas naquele momento, mas certamente evidencia uma dimensão de pertencimento. Era vivida concretamente por meio de experiências de segregação e racismo. Se as fronteiras entre brancos e "negros" podiam ser negociadas e, por vezes, ultrapassadas, existia um sólido lastro social a definir quem era quem.

Por esta razão, ainda que pudesse existir em meados do século XX uma intenção de borramento de fronteiras raciais, a sociedade envolvente nem sempre era receptiva a tal possibilidade de diluição: as práticas sociais e o termo "moreno" definiam claramente quem era quem e, portanto, entre estes, uma percepção de alteridade. Assumo o risco de anacronismo - dado que não se tratava, é evidente, de um contexto de emergência étnica - e o enfrento na medida em que meus dados indicam que se sabia quem era branco e quem não era. Ao menos no trecho supracitado, a última alternativa foi apresentada como opção por parte de alguém que, diga-se de passagem, não se engaja nas mobilizações comunitárias recentes pela titularização de Morro Alto.

Em suma, no caso estudado, ser "moreno" resultava de um compromisso político e afetivo para com a coletividade à qual se pertencia: segundo Gomes (2003: 57), que estudou a mesma comunidade, “'ser moreno' e 'ser negro' têm em comum, além do fato de constituírem-se em oposição a um grupo que se define do mesmo para ambos (os 'de fora'), serem formas de identificação de uma mesma coletividade" (grifos meus). Quer dizer, se a identidade negra passou a ser mobilizada no sentido de conquistas de direitos constitucionais ${ }^{12} \mathrm{e}$ de combate à desigualdade apenas décadas mais tarde, sustento que ela não inaugurou o caráter voluntário da adesão a uma identidade racializada. Ao contrário, acredito que foi a autopercepção como "morenos" que permitiu que a identidade "negra" brotasse.

Talvez os leitores não se sintam suficientemente convencidos do caráter genérico do termo "moreno", em contraposição à descrição de cor individual. Nesse caso, só resta elencar novos exemplos, ${ }^{13}$ que evidenciam os "morenos" como "aqueles que não eram brancos". As já citadas entrevistas que assumem o termo "moreno" a fim de identificar os proibidos de entrar em bailes de brancos indicam a distinção entre um nós/outros de natureza racial. Já o pai de dona Diva e de sua irmã Aurora Inácia Marques da Silva (octogenárias) "não gostava dessa coisa de classificação, de moreno, de branco" ${ }^{14}$ Finalmente, para a primeira, seu avô, "ele é branco, não é moreno". A contraposição branco/moreno, indica que a categoria reside em uma relação de alteridade, antes da descrição de cor: faz as vezes da distinção branco/negro hoje usual. ${ }^{15}$ 
Por vezes "moreno" aparece como uma categoria genérica da qual "preto" ou "negro" aparecem como subcategorias cromáticas. É o que percebemos quando um senhor entrevistado (octogenário) afirma que sua bisavó "era morena preta". ${ }^{16}$ Se minha leitura estiver correta, "preta" adjetiva cromaticamente o substantivo "morena", que diz respeito à condição sociorracial de Felisberta. Percebe-se que no grupo estudado o termo "moreno" nada tem a ver com a mistura racial, sendo empregado desde o mais claro até o mais escuro, designando, em suma, um pertencimento grupal, ainda que constrangido por fronteiras de segregação impostas externamente.

Por vezes, mesmo "negro" define uma subcategoria do termo "moreno". Ao descrever seus vizinhos no Espraiado, dona Aurora enfatizou: "Aí moreno que era negro era cá no Ermenegildo". ${ }^{17}$ Quer dizer, existiam "morenos" em geral, um conjunto maior, e havia subcategorias de cor: "morenos" negros, "morenos" pretos, "morenos" de todos os tipos. O que tinham em comum? Ao que parece, o fato de não serem brancos. $O$ fato de tal significante ser definidor, contrastivamente, de uma coletividade.

\section{Ser "negro" para os idosos}

Para os idosos, a categoria "negro" possui conotação distinta. Se "moreno" remete a uma identificação coletiva, "negro" remete aos seguintes aspectos:

- Ao passado escravista;

- A condições de trabalho degradantes;

- A falta de acesso a direitos.

Conforme mencionado, em fins do oitocentos "negro" remetia à condição escrava (Mattos, 2004: 17). Sua utilização por octogenários e nonagenários de Morro Alto atualiza essa significação. Existe uma lenda em Morro Alto referente a um escravo que matou o senhor, o que fez dele símbolo por excelência da resistência escrava na região (Barcellos et al., 2004; Chagas, 2005). Ele foi referido por dona Diva como "negro". ${ }^{18}$ Quando afirmou que seu avô era branco e pobre $e$, portanto, escravo, a mesma senhora destacou que era "igual aos negros". Existe claro paralelismo entre "negro" e "escravo". ${ }^{19}$ Essa associação está radicalizada quando a senhora Eva emprega o termo para referir-se àqueles que sofriam castigos físicos. ${ }^{20}$ 


\section{Rodrigo de Azevedo Weimer}

Em exemplo revelador, uma prima de ambas, dona Ercília, narrou a história de um naufrágio de navio no "Capão da Negrada". Conforme contou, "Encostou um navio ou naufragou e os negros se espalharam. Então tem negro... O Morro Alto tem muito moreno que é descendente desses negros." 21 O exemplo é eloquente: a categoria "negro" remete ao passado, à escravidão; enquanto os descendentes daqueles homens trazidos por meio do tráfico atlântico eram, no presente, "morenos".

Não apenas ao passado escravista a palavra "negro" remete. Em alguns casos, ela foi utilizada na reflexão sobre a realidade pós-Abolição. Todavia, sempre associada a condições brutais de trabalho, como mostra dona Aurora Inácia Marques da Silva:

Era brabo. Deus do céu. A pessoa trabalhar. E era o clarear do dia. Não tinha relógio. Não tinha nada. Clareava o dia e o negro tinha que saltar e o café era tomado às nove horas. Não era levantar de manhã, encher a barriga e sair. Não. Sair de barriga vazia, às nove horas que tinha o café. Podia trabalhar onde quisesse. Podia ser o serviço que fosse. $^{22}$

A imagem do "negro" é associada ao sofrimento, a vivências brutalizantes, à indiferenciação legada pelo cativeiro e à percepção de sua continuidade após o 13 de maio. É mencionada nos discursos acerca da privação de direitos (Gomes, 2003: 49). Quem não podia entrar no campo de futebol do Grêmio? Os "negros". Quem era desfavorecido pela professora na escola? O "negro". ${ }^{23}$ Quem era ultrajado com o insulto de "macaco"? O "negro". ${ }^{24}$ Quem viu a herança senhorial ser subtraída e vendida por terceiros? Os "negros". ${ }^{25}$ Quem não tinha o direito de casar-se ou ser registrado? O "negro". Quem "não tinha direito a nada"? $\mathrm{O}$ "negro". 26

Assim sendo, é óbvio que a afirmação da identidade individual e, no limite, da própria humanidade, passava pela assunção de formas de designação menos carregadas por significações negativas. ${ }^{27}$ Se existiam experiências inomináveis na realidade escravista (Weimer, 2013), também o pós-Abolição teve aspectos degradantes que era melhor esquecer e que, desse ponto de vista, preencheram o significante "negro". Contrariamente à geração posterior, quando a categoria se converteria em símbolo de orgulho, "negro", então, era associado a situações vergonhosas. ${ }^{28}$

Não é surpreendente, portanto, que os entrevistados idosos em geral se tenham identificado como "morenos", categoria de caráter eufêmico, utilizada por educação, respeito ou estima (Corrêa, 1978). "Negro” aparece, nessa geração, 
Ser "moreno", ser "negro"

como categoria genérica, utilizada na designação de terceiros não-nomeados e nunca como forma de autoidentificação. Sempre na terceira pessoa. ${ }^{29}$

\section{Ser "negro" para os mais novos}

Quando entrevistei Cleci Terra da Silva (quinquagenária), bisneta da escrava Felisberta, ao introduzir um assunto, ela me disse: "Eu como negra vou te dizer uma coisa". ${ }^{30}$ Eu como negra. Há uma ruptura em relação à geração de sua mãe e tias no emprego de termos racializados. Finalizando o artigo, objetivo interpretar tal deslocamento.

Essa autoidentificação pode ser coletiva, como na fala de Wilson Marques da Rosa (quinquagenário), primo em terceiro grau de Cleci e presidente da Associação Comunitária que luta pelo reconhecimento de Morro Alto como remanescente de quilombos. Como liderança comunitária, Wilson assinala uma mudança na correlação de forças a favor do grupo por ele representado, a partir da conclusão do relatório de Morro Alto: "hoje tá uma boa relação, é, pra nós negros, né". ${ }^{31}$

Individual ou coletiva, a percepção do "negro" como eu/nós decorre de uma positivação do termo. ${ }^{32}$ Em lugar das desgraças, sofrimentos e misérias associadas a esse termo pela geração precedente, Cleci se indaga "mas será que o negro não tem tanta coisa boa pra falar?" $33 \mathrm{E}$ arremata, observando o quanto se sente comovida ao ver um "negro" "lá em cima". A ressignificação, portanto, passa por processos de ascensão social vivenciados pela comunidade negra.

Silva e Leão (2012: 128), com efeito, assinalam essa correlação positiva, já que muitos de seus estudados só perceberam a realidade de discriminação e optaram pela assunção de sua negritude ao atingir estratos sociais mais elevados. Por outro lado, entre segmentos populares do Rio de Janeiro que não passaram pelo processo de melhoria de condições de vida desta família - oriunda de um campesinato negro -, o termo "negro" conserva uma dimensão pejorativa (Sheriff, 2001: 223, no que toca à população de um morro carioca, e Silva e Leão, 2012: 129 , no que toca a um recorte da classe trabalhadora). A ascensão social, portanto, está ligada à positivação da categoria "negro".

De forma concomitante ao emprego do termo "negro" sob novas feições, decaiu a utilização de "preto" e "moreno". Cleci não os utilizou uma vez sequer. Seu primo Wilson e sua esposa, Marilda Aparecida Souza da Rosa, falaram em "Preta" apenas ao lembrar o apelido carinhoso de sua mãe/sogra. Jamais como designativo de uma comunidade racial, para o que se emprega "negro". Tampouco o "moreno", tão caro à geração precedente, foi utilizado nas entrevistas. ${ }^{34}$ 


\section{Rodrigo de Azevedo Weimer}

Na fala do presidente da Associação de Moradores de Morro Alto há narrativas de sofrimento. $O$ "negro", entretanto, aparece sobretudo como sujeito de uma luta coletiva: o processo de luta pela "reforma agrária" (cf. Barcellos et al., 2004) é entendido como um "levante negro"; ao falar sobre o Capão da Negrada, Wilson menciona a "resistência negra" numa "Revolução". 35

Da mesma forma, também quando Cleci menciona "os negros" de forma genérica, não se trata de sujeitos inomináveis que passaram por experiências sociais vexatórias, e sim de uma coletividade em busca de direitos de cidadania. Ela relatou, desconfiada, que viu pessoas pobres se cadastrarem na casa de sua mãe almejando a obtenção dos direitos como "remanescentes de quilombos".

Porque uma vez na minha mãe eles vieram, veio um monte de negros com identidade, com tudo, escreveram o nome deles, $\mathrm{e}$ deram o número de identidade e tudo. Sabe, e até bastante gente, tinha bastante gente humilde, simples, que eu até nem sei pra onde é que foi aquilo. $^{36}$

O "negro" é percebido como um sujeito político ativo, um personagem relevante no quadro de relações sociais do Brasil contemporâneo. Isso se dá pelo fato de constituir um povo. Essa última palavra adquire relevo quando percebemos que não está presente apenas na fala da liderança política comunitária - Wilson-, mas também na de uma liderança religiosa em Osório - Cleci -, não envolvida com as demandas das quais o primo é porta-voz.

O "povo negro" é um sujeito político coletivo atuante. Enquanto Cleci se indaga "Aonde que vão arrumar tanta terra naquele Morro Alto pra esse povo negro todo?", Wilson destaca que o "negro" é um povo que tem direitos através de ações afirmativas e que o laudo é um documento de reconhecimento desse po$v o{ }^{37}$ Para além de diversos posicionamentos, há um idioma político comum.

Não há dúvida quanto à importância da mobilização negra na atribulada década de 1980 para a redefinição de significados. No que toca a Osório, existe também o desdobramento dos debates feitos nacionalmente, especialmente em um momento no qual os mais novos não sabem tanto por causa da televisão (cf. Weimer, 2013, capítulo 6). Homens e mulheres, jovens e adultos, estavam informados, naqueles anos, sobre o que acontecia em seu país. No entanto, não acredito que tenha sido apenas isso. Considerar os sujeitos pesquisados como meros consumidores das formulações políticas do movimento negro em um plano nacional é subestimá-los.

Novamente, um paralelo entre Wilson e Cleci pode ser esclarecedor. Ele, um homem político envolvido em lutas sociais e na disputa partidária desde sua 
Ser "moreno", ser "negro"

juventude: partiu ainda moço para Porto Alegre a fim de trabalhar com o deputado Romildo Bolzan, do Partido Democrático Trabalhista. Ela, uma mulher que trabalhou de cozinheira e cafeteira em hotéis quando solteira e, após casar-se, se dedicou às lides como dona de casa e às suas atividades frente à paróquia de Osório.

Com perfis tão distintos, seria de esperar que Wilson tivesse uma "consciência negra" mais aguçada. Isso, no entanto, não ocorre. Ambos utilizaram apenas essa categoria ao problematizar processos de racialização. Mais do que isso, ela foi ainda mais enfática do que seu primo ao destacar-se como negra. Não se tratava apenas de uma identidade pessoal, mas também do lugar de onde falava para propor-me uma assertiva. "Eu como negra vou te dizer uma coisa". A vigorosa condição negra é o que a qualifica para expressar seu ponto de vista a respeito da experiência do grupo de que faz parte.

Vivendo no meio urbano (sua mãe migrou para a cidade no êxodo rural dos anos de 1950), é possível que tenha sofrido a influência de militantes, professores ou vizinhos, a ponto de reformular categorias de classificação racial e de explicação de desigualdades do mundo que a cerca. Estava também sujeita à influência de noticiários na televisão e no rádio, não estava alienada do mundo ao seu redor. Recuso-me, porém, a acreditar que meus entrevistados fossem recipientes vazios a serem "preenchidos" pelas informações do mundo ao redor. Antes, dialogavam com ele.

As práticas ativas de recepção que caracterizam a posição do "leitor" nas formulações recentes acerca da palavra escrita (Certeau, 1994; Chartier, 1998) podem ser pensadas também no que toca ao texto oral ou audiovisual. Admitindo que Cleci tenha adquirido um discurso de "negritude" junto a militantes, professores, vizinhos, televisão, rádio, todos juntos, isso só foi possível por estar embebida em um caldo cultural específico que possibilitou uma apropriação criativa.

Identifiquei três aspectos cruciais nessa releitura. Em primeiro lugar, as experiências de discriminação enfrentadas desde a infância por qualquer indivíduo "moreno", "preto", "negro" - o que for - tornam-no propício à recepção de um discurso de resistência e orgulho. Em segundo lugar, as trajetórias de ascensão social de "negros" e a conquista de "um lugar ao sol" foram palpáveis para Cleci, e devidamente sublinhadas em sua fala. Trata-se de um fenômeno objetivo. Finalmente, e este parece ser o elemento mais importante, se há, por um lado, uma ruptura com a geração anterior no significado atribuído ao termo "negro", por outro, mesmo entre pais e avós existia uma consciência das hierarquias sociais que racializavam os indivíduos e uma percepção arguta de quem éramos "nós" e de quem eram "eles". As experiências de racialização foram reelaboradas. Sua memória, contudo, opera no presente. 


\section{Rodrigo de Azevedo Weimer}

\section{Fim, ou novos começos}

Aos meus olhos, a expressão de diferenças raciais por meio da noção de "morenos" não representou um esforço por branqueamento. É ingênuo ignorar suas solidariedades e crer que todos quisessem ser brancos. É necessário dar crédito ao senhor que afirmou querer ser moreno. Alguns tiveram perspectivas de branqueamento - muitas vezes, mal sucedidas (Weimer, 2013) -, mas muitos apostaram na solidariedade comunitária. Por outro lado, tudo indica que se quisessem afastar de uma identidade negativa representada pelo termo "negros". A partir do momento em que essa categoria foi positivada, tornou-se preferencial para expressar as experiências de racialização. Houve uma ruptura, sim. Mas essa ruptura, contraditoriamente, deu-se sob o signo da herança.

Se, com frequência, essa continuidade é minimizada e o termo "negro" é absolutizado pelos movimentos sociais como o único pelo qual se pode expressar uma "consciência crítica", é porque "a identidade grupal só parece funcionar ou, pelo menos, funcionar melhor - quando é vista por seus membros como natural, como 'real'" (Appiah, 1997: 244). Creio que isso faz parte do processo de legitimação do movimento negro contemporâneo e da afirmação de quaisquer movimentos sociais. Não cabe ao intelectual prescrever modelos identitários. Não obstante, é necessário inseri-los na historicidade e perceber seu enraizamento em uma herança doméstica: já foi devidamente sublinhado o papel familiar na “descoberta da negritude" (Alberti e Pereira, 2007: 37-48).

Não me parece legítimo secundarizar o papel das gerações precedentes ou menosprezar o vocabulário a partir do qual elas expressaram uma identidade racial. Foi a herança de uma consciência de alteridade, expressa pelo termo "morenos", que permitiu que a geração posterior se descobrisse "negra". Ser "moreno", ser "negro": no caso de Morro Alto, o solo fértil da autopercepção dos idosos possibilitou a emergência de uma nova categoria.

Seria temerário - e não foi a minha intenção - pretender generalizações nacionais, ou mesmo estaduais, com base em um estudo realizado a partir de apenas uma família sita em uma região pouco expressiva em termos econômicos e políticos no Rio Grande do Sul, estado cuja dinâmica racial muitas vezes foi percebida como portadora de especificidades perante o restante do país (Cardoso, 1977). Ainda assim, creio que este estudo particularizado acerca da categoria "morenos" poderá oferecer elementos - especialmente a necessidade de percebê-los em uma dimensão histórico-geracional - e indagações para análises da mesma natureza em outros lugares do Brasil, a fim de verificar regularidades ou discrepâncias nos usos desta forma de identificação.

Dados referentes à Pesquisa Nacional por Amostras de Domicílios do Instituto Brasileiro de Geografia e Estatística (1976) e a uma pesquisa de 2008 do 
Ser "moreno", ser "negro"

Datafolha assinalam, respectivamente, uma identificação espontânea de 35,7\% e $27 \%$ da população do país como "morena" (apud Silva e Leão, 2012). Isso sugere um grande vigor da categoria, provavelmente mesmo diante de uma população mais jovem. É possível que a "transição" entre "moreno" e "negro" por mim constatada seja uma especificidade da família ou da região estudadas. Inclino-me mais para a segunda alternativa, dado que Gomes (2003) encontrou resultados similares ao estudar, como um todo, a comunidade da qual a família analisada faz parte. Não se pode desprezar, é evidente, a importância da mobilização étnica naquele local, que pode ter incidido mesmo sobre aqueles que não fizeram parte diretamente da família. A transição pode resultar, ainda, de oportunidades de ascensão social sui generis de uma família oriunda de um campesinato negro com acesso estável à terra no pós-Abolição. De toda forma, conclusões mais genéricas e apuradas sobre os "morenos" dependerão, certamente, de estudos referentes a outros estados, regiões e localidades do Brasil. Espero que este artigo possa ter apresentado alguma contribuição para instigar novas pesquisas e novos debates.

Notas

1. Assim, a realização de entrevistas de história oral não serviu tanto como fonte para a obtenção de informações, e sim como objeto de problematização acerca da memória. Todas as entrevistas citadas foram realizadas pelo autor, à exceção da entrevista com a senhora Ercília Marques da Rosa e com Wilson Marques da Rosa, feita por Cíntia Müller, Mariana Fernandes, Alessandro Gomes e Cíntia Rizzi. À exceção desta, da entrevista com a senhora Aurora Inácia Marques da Silva, senhora Diva Inácia Marques Terra e senhor Celso Terra e, ainda, das entrevistas anônimas, as demais encontram-se depositadas no Laboratório de História Oral e Imagem da Universidade Federal Fluminense. Foram explicitados os nomes dos entrevistados que concodaram por meio de autorização escrita.

2. Por meio do paralelo traçado entre a condição escrava dos avós e a precariedade no acesso a direitos trabalhistas em mea- dos do século-sobretudo para as mulheres (Weimer, 2013).

3. Osório e Maquiné são municípios oriundos da antiga Conceição do Arroio. Em 1934, o município mudou de nome para Osório, por determinação do interventor federal José Antônio Flores da Cunha. Em 1992, o distrito de Maquiné obteve sua emancipação.

4. Entrevista com a senhora Eva Marques Correia no dia 14 de janeiro de 2009 no Caconde.

5. Entrevista filmada com a senhora Diva Inácia Marques Terra no dia 12 de março de 2010 em Osório.

6. Entrevista filmada com a senhora Eva Marques Correia no dia 12 de março de 2010 no Caconde.

7. Entrevista no dia 12 de janeiro de 2009 em Porto Alegre. Há outros exemplos que indicam a distinção branco/moreno no 


\section{Rodrigo de Azevedo Weimer}

que toca à admissão em bailes. Entrevista com a senhora Adiles Marques de Oliveira no dia 26 de janeiro de 2009 em Porto Alegre; entrevista com a senhora Maria Inácia Marques no dia 7 de janeiro de 2009 em Osório; entrevista com a senhora Eva Marques Correia em 14 de janeiro de 2009 no Caconde. Efetivamente, tal vocabulário foi acionado de forma recorrente com fins de descrição das barreiras de segregação.

8. Entrevista no dia 12 de janeiro de 2009 em Porto Alegre. Grifos meus.

9. Assim, a fala do entrevistado oferece elementos para o questionamento de uma ideia largamente disseminada nas ciências sociais brasileiras desde Oracy Nogueira (1985, [original de 1954]) e Marvin Harris (1967, [original de 1964]), segundo os quais o preconceito de marca presente no Brasil seria definido tão-somente pelo fenótipo. Também Sheriff (2001: 231), em seu estudo sobre um morro carioca, assinala a importância da ascendência, e não apenas do fenótipo, na definiçãa da situação racial.

10. Diante da fácil e rasa interpretação de que essa fala resultaria de uma racionalização de sua falta de opções de inserção racial, prefiro acreditar na sinceridade do depoimento do entrevistado. Afinal, sozinho com o entrevistador, ele poderia ter-se atribuído a classificação que quisesse, inclusive a de "branco"... Optou por "moreno"!

11. Para Gilroy, a identidade negra não é uma mera categoria social e política a ser utilizada conforme as flutuações do poder de persuasão da retórica que a apoia ou legitima. "Seja o que for que os construcionistas radicais possam dizer, ela é vivida como um sentido experencial coerente (embora nem sempre estável) do eu [self]" (Gilroy, 2001: 209). Isso tornou possível ao entrevistado, na contramão daquilo que Gilroy qualifica como "absolutismo étnico", considerar-se "negro" não obstante um fenótipo de branco, já que suas experiências pessoais o levaram a isso.

12. Refiro-me ao artigo 68 dos atos das Disposições Constitucionais Transitórias, relativo aos direitos das comunidades remanescentes de quilombos.

13. Ao referir-me a categorias racializadas nas questões de minhas entrevistas, fatalmente utilizei algumas palavras cromáticas ou raciais ao indagar os entrevistados. Para não dar espaço a induções, apresento apenas exemplos nos quais esses termos classificatórios apareceram espontaneamente na fala dos sujeitos pesquisados.

14. Entrevista realizada com a senhora Aurora Inácia Marques da Silva, senhor Celso Rodrigues Terra e senhora Diva Inácia Marques no dia 28 de novembro de 2001 em Osório.

15. Entrevista com a senhora Diva Inácia Marques Terra no dia 16 de janeiro de 2010 em Osório.

16. Entrevista no dia 11 de fevereiro de 2009 em Porto Alegre.

17. Entrevista com a senhora Aurora Inácia Marques da Silva no dia 9 de janeiro de 2009 em Osório.

18. Entrevista com a senhora Diva Inácia Marques Terra no dia 16 de janeiro de 2010 em Osório.

19. Entrevista com a senhora Diva Inácia Marques Terra no dia 12 de março de 2010 em Osório.

20. Entrevista com Arli Marques Correia e Maria Marques Correia Mendes no dia 19 de novembro de 2010 no Caconde.

21. Entrevista com a senhora Ercília Marques da Rosa e Wilson Marques da Rosa no dia 26 de agosto de 2001.

22. Entrevista com as senhoras Aurora Inácia Marques da Silva e Eva Inácia 


$$
\text { Ser "moreno", ser "negro" }
$$

Marques no dia 9 de janeiro de 2010 em Osório. Grifo meu.

23. Entrevista com o senhor Manoel Inácio Marques Neto no dia 9 de janeiro de 2009 em Osório.

24. Entrevista com Arli Marques Correia e Maria Marques Correia Mendes no dia 19 de novembro de 2010 no Caconde.

25. Entrevista com a senhora Aurora Inácia Marques da Silva, senhor Celso Rodrigues Terra e a senhora Diva Inácia Marques no dia 28 de janeiro de 2001 em Osório.

26. Entrevista com a senhora Aurora Inácia Marques da Silva e Eva Inácia Marques no dia 9 de janeiro de 2010 em Osório.

27. Mello (2012: 84, 100-102) também assinalou a preferência pelo termo "moreno" ao termo "negro", considerado uma palavra "muito aguda" na comunidade gaúcha de Cambará, por ele estudada.

28. "Embora a cor de pele associada a essa classificação seja a 'negra', 'os morenos' é uma designação considerada hoje [2003] menos pejorativa, indicando uma possível estratégia de alteração de designação em função da carga altamente pejorativa atribuída ao termo 'negro'.” (Gomes, 2003: 59)

29. Pollak (2000: 238-244) realizou profícua análise das formas pronominais nas entrevistas por ele feitas com sobreviventes de campos de concentração, constatando, amparado no linguista Benveniste, que a terceira pessoa é uma não-

\section{Referências bibliográficas}

ALBERTI, Verena e PEREIRA, Amilcar Araújo. Histórias do movimento negro no Brasil. Rio de Janeiro: Pallas, CPDOC-FGV, 2007. pessoa, na medida em que remete sempre à impotência, a situações e estruturas, e não a indivíduos que possam ser apontados.

30. Entrevista com Cleci Terra da Silva no dia 21 de novembro de 2010 em Osório.

31. Entrevista com Wilson Marques da Rosa e Marilda Aparecida Souza da Rosa no dia 20 de janeiro de 2010 em Capão da Canoa.

32. Infelizmente, não me sinto habilitado a datá-la. O fato é que em fins dos anos de 1970 , o termo "negro" ainda era relegado como pejorativo e ainda se privilegiava a categoria "moreno" (Corrêa, 1978).

33. Entrevista com Cleci Terra da Silva no dia 21 de novembro de 2010 em Osório.

34. Entrevista com Wilson Marques da Rosa e Marilda Aparecida Souza da Rosa no dia 20 de janeiro de 2010 em Capão da Canoa.

35. Idem. Infelizmente, não consegui apurar de que processo revolucionário se trata. A Revolução Farroupilha? A Federalista? 1923? 1930? Não sei.

36. Entrevista com Cleci Terra da Silva no dia 21 de novembro de 2010 em Osório. Grifo meu.

37. Idem. Grifo meu. Entrevista com Wilson Marques da Rosa e Marilda Aparecida Souza da Rosa no dia 20 de janeiro de 2010 em Capão da Canoa.
APPIAH, Kwame Anthony. Na casa do meu pai. A África na filosofia da cultura. Rio de Janeiro: Contraponto, 1997. 
BARCELLOS, Daisy M.; CHAGAS, Miriam de Fátima; FERNANDES, Mariana Balen; FUJIMOTO, Nina Simone; MOREIRA, Paulo Roberto Staudt; MÜLLER, Cíntia Beatriz; VIANNA, Marcelo; WEIMER, Rodrigo de Azevedo. Comunidade negra de Morro Alto. Historicidade, identidade e direitos constitucionais. Porto Alegre: Editora da UFRGS, 2004.

BERLIN, Ira. Gerações de cativeiro. Uma história da escravidão nos Estados Unidos. Rio de Janeiro: Record, 2006.

CARDOSO, Fernando Henrique. Capitalismo e escravidão no Brasil Meridional. $O$ negro na sociedade escravocrata do Rio Grande do Sul. Rio de Janeiro: Paz e Terra, 1977.

CERTEAU, Michel de. A invenção do cotidiano. $9^{\text {a }}$ ed. Petrópolis: Vozes, 1994.

CHAGAS, Miriam de Fátima. Reconhecimento de direitos face aos (des) dobramentos da História: um estudo antropológico sobre territórios de quilombos. Tese de doutorado em Antropologia Social, Universidade Federal do Rio Grande do Sul. Porto Alegre: 2005.

CHARTIER, Roger. Escribir las prácticas: discurso, práctica, representación. $1^{\text {a }}$ ed. Valencia: Fundación Cañada Blanch, 1998.

CORRÊA, Norton. Os negros do Morro. In: Correio do Povo, 21 de janeiro de 1978.

CRAPANZANO, Vincent. Estilos de interpretação e a retórica de categorias sociais. In: MAGGIE, Yvonne e REZENDE, Claudia B. Raça como retórica - a construção da diferença. Rio de Janeiro: Civilização Brasileira, 2001.

GILROY, Paul. O Atlântico negro. São Paulo: Ed. 34/ Rio de Janeiro: Universidade Candido Mendes, Centro de Estudos AfroAsiáticos, 2001.

GOMES, Alessandro Garcia. O processo de manipulação de identidades em uma comunidade a partir de um processo de intervenção institucional. Dissertação de mestrado em An- tropologia Social, Universidade Federal do Rio Grande do Sul. Porto Alegre, 2003.

GOMES, Flávio. Negros e política (18881937). Rio de Janeiro: Jorge Zahar Editor, 2005.

HARRIS, Marvin. Padrões raciais nas Américas. Rio de Janeiro: Civilização Brasileira, 1967. [original de 1964].

HARTOG, François. Régimes d'historicité. Présentisme et expériences du temps. Paris: Editions du Seuil, 2003.

MATTOS, Hebe Maria. Marcas da escravidão. Biografia, racialização e memória do cativeiro na história do Brasil. Tese de Professor Titular em História, Universidade Federal Fluminense. Niterói, 2004.

Memórias do cativeiro: narrativa e identidade negra no antigo Sudeste cafeeiro. In: RIOS, Ana e - Memórias do cativeiro: família, trabalho e cidadania no pós-Abolição. Rio de Janeiro: Civilização Brasileira, 2005.

MELLO, Marcelo Moura. Reminiscências dos quilombos. Territórios da memória em uma comunidade negra rural. São Paulo: Editora Terceiro Nome, 2012.

NOGUEIRA, Oracy. Preconceito racial de marca e preconceito racial de origem: sugestão de um quadro de referência para a interpretação do material sobre relações raciais no Brasil. In: Tanto preto quanto branco: estudos de relações raciais. São Paulo: T. A. Queiroz, 1985. [original de 1954].

PEREIRA, Amílcar Araujo. "O mundo negro". A constituição do movimento negro contemporâneo no Brasil (1970-1995). Tese de doutorado em História, Universidade Federal Fluminense. Niterói, 2010.

POLLAK, Michael. L'expérience concentrationnaire. Essai sur le maintien de l'identité sociale. Paris : Ed. Métailié, 2000.

ROUSSO, Henry. A memória não é mais o que era. In: FERREIRA, Marieta de Mo- 
Ser "moreno", ser "negro"

raes e AMADO, Janaína. Usos e abusos $d a$ história oral. Rio de Janeiro: FGV/Editora da UFRJ, 1998.

SANSONE, Livio. Negritude sem etnicidade. Salvador: Edufba/ Rio de Janeiro: Pallas, 2003.

SHERIFF, Robin. Como os senhores chamavam os escravos: discursos sobre cor, raça e racismo num morro carioca. In: MAGGIE, Yvonne e REZENDE, Claudia Barcellos. Raça como retórica. A construção da diferença. Rio de Janeiro: Civilização Brasileira, 2001.

SILVA, Graziella Moraes e LEÃO, Luciana T. de Souza. O paradoxo da mistura. Identidades, desigualdades e percepção de discriminação entre brasileiros pardos. In: Revista Brasileira de Ciências Sociais, vol. 27, $\mathrm{n}^{\mathrm{o}} 80$, outubro 2012.
WEIMER, Rodrigo de Azevedo. A gente da Felisberta. Consciência histórica, história e memória de uma família negra no litoral rio-grandense no pós-emancipação. (c.1847 - tempo presente). Tese de doutorado em História, Universidade Federal Fluminense. Niterói, 2013.

WOLIKOW, Serge. Lhistoire du temps présent en question. In: - e PORRIER, Philippe. Territoires contemporains. Où en est l'histoire du temps présent? Actes du Colloque Transfrontalier - Cluse. Bulletin de l'Institut d'Histoire Contemporaine, $\mathrm{n}$. 5. Dijon, 1998. Disponível on-line em http://tristan.u-bourgogne.fr/umr5605/pu blications/ouenesthistoiretemps/ouenhisto iretempspresent.pdf. Acesso em 14 de outubro de 2011.

\section{Resumo}

O artigo estuda a passagem da designação racial de "moreno" para "negro" no litoral norte do Rio Grande do Sul, entre a geração de netos e bisnetos de escravos, isto é, entre meados do século XX e início do século XXI. A historicização, através da memória, das categorias de identificação racial permite desnaturalizar a categoria "negro" como a única expressão de uma identidade étnica e, pelo contrário, reconhece o valor das percepções dos idosos acerca de seu pertencimento racial.

Palavras-chave: racialização, "moreno", "negro".

\section{Abstract}

The article studies the passage of the racial designation from "moreno" to "negro" in the north coast of the Brazilian state of Rio Grande do Sul. This passage happened between the generations of grandsons and great-grandsons of slaves, namely from the middle of the $\mathrm{XX}^{\text {th }}$ century to the beginning of the $\mathrm{XXI}^{\text {th }}$ century. By historicizing, through memory, the categories of racial identification, we are able to denaturalize the "negro" category as the only possible expression of an ethnic identity, and instead recognize the value of the elders perceptions about their racial belonging.

Keywords: racialization, "moreno", "negro". 


\section{Rodrigo de Azevedo Weimer}

\section{Résumé}

Cet article étudie le passage de la désignation raciale de "moreno" à "negro" dans le littoral nord de l'état brésilien du Rio Grande do Sul. Ce passage a eu lieu entre les générations de petits-fils et arrière-petits-fils d'esclaves, c'est à dire entre la moitié du XX ${ }^{\text {ème }}$ siècle et le début du XXI ${ }^{\text {ème }}$. L'historicisation, à travers la mémoire, des catégories d'identification raciale permet de dénaturaliser la catégorie "negro" comme expression unique d'une identité ethnique et reconnaît l'importance de la perception des plus âgés sur leur appartenance raciale.

Mots-clés: racialisation, "moreno", "negro". 